\title{
Reversible airway obstruction in cystic fibrosis
}

\author{
L P ORMEROD, R A THOMSON, CHARLOTTE M ANDERSON, AND D E STABLEFORTH \\ From the Institute of Child Health, University of Birmingham, and East Birmingham Hospital, Birmingham
}

ABSTRACT Fourteen (29\%) of 48 children with cystic fibrosis had a greater than $15 \%$ improvement in forced expiratory volume in one second, or in forced vital capacity after inhalation of salbutamol. All these children were atopic (one or more positive prick tests) and had a significantly higher mean serum IgE than either non-atopic subjects or those atopic subjects without airways reversibility ( $\mathrm{p}<\infty_{\infty}$ 0.02). Half of those with airways reversibility had or subsequently developed the clinical picture of 0 allergic bronchopulmonary aspergillosis. Of the whole group $81 \%$ were atopic, of whom $77 \%-$ had a positive reaction to $A$ fumigatus, $64 \%$ to housedust, and $56 \%$ each to grass pollen and cat $\bigcirc$ hair. Children who were not atopic had significantly better spirometry $(\mathrm{p}>0.05)$ than those who 0 were. Children with skin hypersensitivity to $A$ fumigatus had identical spirometry to those who were atopic without reactivity to $A$ fumigatus. Serum precipitins to $A$ fumigatus were present in $\vec{\bullet}$ $48 \%$. Serum precipitins to pancreatin were present in $71 \%$, but the presence of these precipitins ${ }^{\circ}$ did not correlate with atopy, airways reversibility, or serum IgE.

The prevalence and significance.: of abnormal airways function in cystic fibrosts has been the subject of debate for many years. Derbes et al ${ }^{1}$ reported non-allergic asthma in cystic fibrosis in $48 \%$ of patients, but this diagnosis was from a history of wheezing and was not confirmed physiologically. The frequency of airways disease found physiologically has varied considerably depending on the methods used. Day and Mearns $^{2}$ found abnormal bronchial lability on exercise testing, $50 \%$ having abnormal bronchodilatation during exercise, and $46 \%$ abnormal bronchoconstriction after exercise. Counahan and Mearns ${ }^{3}$ reported $40 \%$ abnormal bronchoconstriction after standardised exercise testing. Rachelefsky et $a l^{4}$ found $14 \%$ of patients had an increase of $15 \%$ or more in the FEV after isoprenaline or epinephrine. More recently Silverman et $a l^{5}$ found $22 \%$ of patients had abnormal airways lability on exercise testing, and Mitchell et al, ${ }^{\mathbf{6}}$ using methacholine challenge, found $51 \%$ of patients to have abnormal responses. It is not surprising that airways lability is found in cystic fibrosis, since chronic pulmonary infection is a major part of the disease. The characteristics of the bronchial lability in cystic fibrosis have been shown to be different from those in classical asthma. ${ }^{2} 56$ This

Address for reprint requests: Dr LP Ormerod, North Manchester General Hospital, Crumpsall, Manchester M8 6RB. has lead to the comment ${ }^{7}$ that in practical terms frank asthma in cystic fibrosis is rare.

The significance of positive prick tests to various inhaled allergens, which occur frequently을 in cystic fibrosis, is also a subject of debate. This finding is consistent with impaired handling of antigens at the mucosal surface of the respiratory tract leading to an increased frequency of $\vec{*}$ immediate skin hypersensitivity. Some workers, $89 \frac{9}{9}$ however, have suggested that because of an increase in atopy in obligatory CF heterozygotes 3 some of the increased prevalence of skin hyper-i sensitivity may be a primary abnormality. Other results $^{3} 5$ do not support this contention.

Our impression was that asthma in cystic $^{?}$ fibrosis was not rare, and this survey was under $-\frac{D}{0}$ taken to determine the frequency of physiological airways reversibility in our own clinic, relating $N$ it to immunological and skin hypersensitivity findings. Because of reports of pancreatin-N induced airways obstruction, ${ }^{10-12}$ an assessment ${ }^{\omega}$ of immunological reaction to pancreatic extract was included in the survey. The children tested? were those of 5 years and over who could produces reliable spirometry seen over a six-month period in the clinic.

\section{Methods}

Forty-eight children ( 24 boys and 24 girls) witk cystic fibrosis (sweat sodium $>60 \mathrm{mmol} / \mathrm{l}$ ) 
regularly attending the cystic fibrosis clinic were studied. No selection was made other than that reproducible spirometry could be obtained, and parents gave informed consent. The age range was 5-18 years, mean 10.7 years. Twenty-four had a history of allergic disease in first degree relatives.

Spirometry was performed using a Vitalograph dry spirometer read at BTPS. The children performed several trial forced vital capacity manoeuvres (FVC), then three consecutive FVC manoeuvres were made. Salbutamol $(200 \mu \mathrm{g})$ was then given by pressurised aerosol. Three further consecutive FVC manoeuvres were recorded 10 minutes later. A single observer was used throughout the study. The mean forced expiratory volume in one second $\left(\mathrm{FEV}_{1}\right)$ and mean FVC were measured before and after bronchodilator. The mean $\mathrm{FEV}_{1}$ and FVC before bronchodilator were expressed as a percentage of the predicted value for height-matched normal children. ${ }^{13} \mathrm{~A}$ rise of $15 \%$ or more in either the $\mathrm{FEV}_{1}$ or the FVC after bronchodilator was taken to be a clinical response.

Prick skin testing was performed on the forearm using 12 standard Bencard skin test antigens: grass pollen B2 $(2.5 \%)$; tree pollen B3 $(2.5 \%)$; mixed feathers $(150 \%)$; cat fur $(150 \%)$; dog hair (150\%); whole egg (6\%); cow's milk $(10 \%) ;$ Aspergillus terreus $(5 \%) ;$ Aspergillus fumigatus (5\%); mixed moulds M10 (10\%); house dust (150\%); Dermatophagoides pteronyssinus $(1 \cdot 2 \%)$; and a control solution. Reactions were examined after 15 minutes, and were considered positive if there was a weal of $3 \mathrm{~mm}$ or greater. No patient reacted to the control solution. Parents were asked to measure the weal to $A$ fumigatus after five hours using the same criteria. A blood eosinophil count, and a number of serological tests were carried out. IgG, IgA, and IgM were measured by single radial diffusion using specific antisera. ${ }^{14}$ IgE was measured by the radioactive single diffusion test. ${ }^{15}$ Aspergillus precipitins were measured by double diffusion in agar gel using antigen supplied by Bencard in a method recommended by the suppliers. Pancreatin precipitins were measured by a similar double diffusion technique using $5 \%(\mathrm{w} / \mathrm{v})$ solution of Pancrex $\mathrm{V}$ powder, made up fresh on each occasion. Faint single lines only visible after drying and staining were regarded as weak positives, strong precipitin lines visible in the unstained preparation were recorded as "strong" positives.

Statistical analysis was by $t$ test, $\chi^{2}$ test, correlation coefficient, or by Mann-Whitney $U$ test as appropriate.

\section{Results}

The mean $\mathrm{FEV}_{1}$ was $69.8 \%$ (SD 25.0) of predicted and the mean FVC $82.5 \%$ (SD 23.4) of predicted. Fourteen patients showed an increase of $15 \%$ or more in $\mathrm{FEV}_{1}$ or FVC or both after bronchodilator. Six patients had a significant increase in $\mathrm{FEV}_{1}$ alone, four in both $\mathrm{FEV}_{1}$ and FVC, and four in FVC alone (table 1). Ten of these patients had a history of wheeze or nocturnal cough. The mean $\mathrm{FEV}_{1}$ and FVC before bronchodilator of those patients showing $>15 \%$ reversibility were not significantly different from those of the subjects without reversibility (for $\mathrm{FEV}_{1} t=1 \cdot 19$; for FVC $t=0.67$ ). The mean age of patients with reversibility was 9.6 years \pm 2.09 and was less than that of non-responders $11 \cdot 2$ years \pm 3.07 ; this difference was not significant $(0 \cdot 1>\mathrm{p}>0.05)$.

Patients were regarded as atopic if there was one or more significant response. Thirty-nine children were atopic (mean age 10.9 years), nine were non-atopic (mean age $\mathbf{9 . 8 8}$ years); this difference was not significant $(t=1 \cdot 14)$. Thirty children had an immediate positive reaction to $A$ fumigatus, 10 children had a dual (immediate and delayed (five hours) reaction. Four of the children with this pattern fulfilled diagnostic criteria for allergic bronchopulmonary asper-

Table 1 Results of spirometry in responders to salbutamol

\begin{tabular}{llll}
\hline Parameter & Number & $\begin{array}{l}\text { Mean increase } \\
\text { in FEV } 1\end{array}$ & $\begin{array}{l}\text { Mean increase } \\
\text { in FVC }\end{array}$ \\
\hline $\begin{array}{l}>15 \% \text { increase } \\
\text { in FEV } 1 \text { alone }\end{array}$ & 6 & $20.0 \%$ & $7.9 \% *$ \\
$>\begin{array}{l}15 \% \text { increase } \\
\text { in FEV } 1 \text { and FVC } 4\end{array}$ & $21.7 \%$ & $20 \cdot 5 \%$ \\
$>\begin{array}{l}15 \% \text { increase } \\
\text { in FVC alone }\end{array}$ & 4 & $7.9 \% *$ & $17.0 \%$ \\
\hline
\end{tabular}

*These increases were not to a significant level.

Table 2 Skin testing results in atopic subjects $(n=39)$

\begin{tabular}{llll}
\hline Allergen & Negative & Positive & $\%$ Positive \\
\hline Grass pollen & 17 & 22 & 56 \\
Tree pollen & 29 & 10 & 26 \\
Mixed feathers & 28 & 11 & 28 \\
Cat fur & 17 & 22 & 56 \\
Dog hair & 29 & 10 & 26 \\
Whole egg & 37 & 2 & 5 \\
Cow's milk & 34 & 5 & 13 \\
A terreus & 19 & 20 & 51 \\
A fumigatus & 9 & 30 & 77 \\
Mixed moulds & 25 & 14 & 36 \\
House dust & 14 & 25 & 64 \\
D pteronyssinus & 24 & 15 & 38 \\
\end{tabular}


Table 3 Atopic status in relation to spirometry

\begin{tabular}{|c|c|c|c|}
\hline & \multirow[t]{2}{*}{ Non-atopic } & \multicolumn{2}{|l|}{ Atopic } \\
\hline & & $\begin{array}{l}\text { A fumigatus and } \\
\text { other allergens }\end{array}$ & $\begin{array}{l}\text { Other allergens } \\
\text { only }\end{array}$ \\
\hline $\begin{array}{l}\text { Number } \\
\text { Age (yr) } \\
\text { FEV } \% \% \\
\text { FVC } \%\end{array}$ & $\begin{array}{l}9 \\
9 \cdot 88(2 \cdot 77) \\
86 \cdot 94(19 \cdot 0)^{*} \\
99 \cdot 75(17 \cdot 0)^{*} \dagger\end{array}$ & $\begin{array}{l}30 \\
11 \cdot 36(3 \cdot 13) \\
66 \cdot 95(26 \cdot 0) \\
81 \cdot 30(24 \cdot 8) \ddagger\end{array}$ & $\begin{array}{l}9 \\
9 \cdot 38(1 \cdot 39) \\
70 \cdot 0(23 \cdot 0) \\
81 \cdot 0(18 \cdot 7)\end{array}$ \\
\hline
\end{tabular}

Standard deviations in parentheses.

*Significantly greater than atopic group $1 \mathrm{p}>0.05$

†Significantly greater than atopic group $2 p>0.05$

$\ddagger$ Not significantly different from atopic group $2 \mathrm{p}>0.95$

Table 4 Variation of type 1 skin test to $A$ fumigatus with age

\begin{tabular}{lrrrrrrrrrrrrr}
\hline Age(yr) & 5 & 6 & 7 & 8 & 9 & 10 & 11 & 12 & 13 & 14 & 15 & 16 & 17 \\
Positive & 1 & 0 & 4 & 4 & 3 & 6 & 3 & 1 & 3 & 4 & 2 & 1 & 1 \\
Negative & 1 & 0 & 3 & 3 & 2 & 3 & 1 & 1 & 1 & 0 & 0 & 0 & 0 \\
$\%$ Positive & 50 & - & 57 & 57 & 60 & 67 & 75 & 50 & 75 & 100 & & & $\longrightarrow$ \\
\hline
\end{tabular}

gillosis. ${ }^{16}$ Reactions to $A$ fumigatus did not occur as an isolated positive skin test, but gave a type 1 skin reaction more commonly than any other allergen tested. There was no significant reversibility in the non-atopic group. Table 2 shows the reactions to various allergens in the atopic group, table 3 shows the relationship of skin reactivity and spirometry, and table 4 the relationship of type 1 A fumigatus skin hypersensitivity to age.

The mean IgG was $11.96 \mathrm{gm} / 1$ (SD 5.67), the mean IgA was $2.19 \mathrm{gm} / 1$ (SD 1.30), and the mean IgM $1.00 \mathrm{gm} / 1$ (SD 0.5). One child showed selective IgA deficiency. The mean IgE was 469 $\mathrm{IU} / \mathrm{ml}$ (range 50-7200). The figure shows the IgE range of different subgroups. There was no overall correlation between the $\mathrm{FEV}_{1}$ and the serum $\operatorname{IgE}(\mathrm{r}=0 \cdot 24 ; \mathrm{p}=0 \cdot 1)$.

Twenty-three patients ( $48 \%$ ) had positive serum precipitins to $A$ fumigatus, being associated in 17 cases with an immediate positive skin test. Thirteen patients had an immediate positive skin test with negative serum precipitins.

Serum precipitins to pancreatin were measured in all patients. Fourteen showed a negative response, 12 a weak positive, and 22 a strong positive reaction. There were no differences between these subgroups in terms of age, immunoglobulins $A, G, M$, and E, FVC, or in the frequency of atopy, airways reversibility, or presence of Aspergillus precipitins. The only significant difference was that the mean $\operatorname{FEV}_{1}(84 \cdot 1 \%)$ of children with negative pancreatin precipitins was significantly higher $(p>0.05)$, than that of those with either weak positive (mean $\mathrm{FEV}_{1} 64.3 \%$ ) or strong positive (mean $\mathrm{FEV}_{1} \mathbf{6 6 . 4 \%}$ ) pancreatin precipitins.

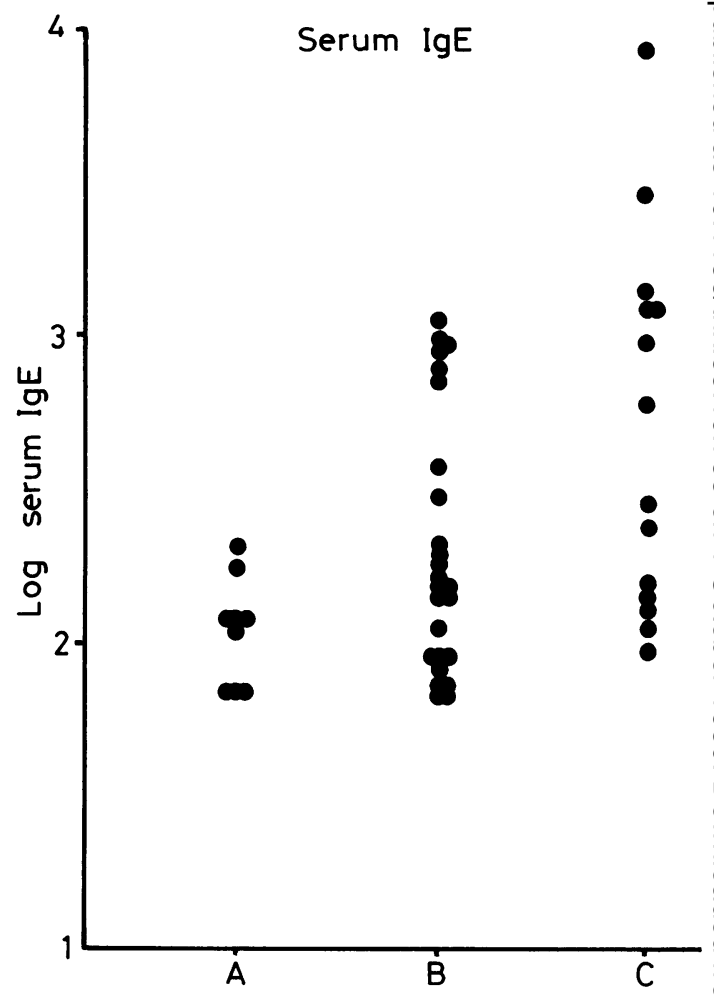

Figure Log of serum $\operatorname{IgE}(I U / \mathrm{ml})$ in $(A)$ non-atopic patients, (B) atopic patients with no airways reversibility, and $(C)$ atopic patients with airways reversibility. Statistical significance (Mann-Whitney $U$ test) $A$ versus $B p=0.04, B$ versus $C p=0.015$, $C$ versus $A$ p $=0.001$.

Eosinophilia greater than $0.4 \times 10^{9} \mathrm{l}^{-1}$ was found in only two patients at the time of testing. The $\frac{\mathrm{O}}{3}$ values of $1.86 \times 10^{9} / 1$ and $1.19 \times 10^{9} / 1$ were in children who fulfilled the clinical criteria for allergic bronchopulmonary aspergillosis. ${ }^{16}$ In all $\frac{D}{0}$ six children fulfilled these criteria. A further child had asthma, previous blood eosinophilia N an immediate positive skin test to $A$ fumigatus, and a serum IgE of $7200 \mathrm{IU} / \mathrm{ml}$. No lung shadowing was seen at the time of these investigations, $\omega$ but it was felt that she was developing the disease. Subsequently she developed lung shadow을 ing with an associated blood eosinophilia and details have been reported elsewhere. ${ }^{17}$

\section{Discussion}

Eighty-one per cent of the children tested were $\stackrel{\mathbb{Q}}{2}$ atopic, which is in keeping with the reported prevalence when tests including $A$ fumigatus are 
used. $^{3} 1819$ In those children who were atopic, $A$ fumigatus hypersensitivity was most frequent, but was always accompanied by at least one other positive response to a common allergen. Positive responses to fungal antigens such as $A$ fumigatus are common in cystic fibrosis, and some authors have held that this factor has inflated the frequency of atopy in cystic fibrosis. ${ }^{5}$

The serum IgE of the non-atopic group was significantly lower than that of the atopic group, which was again lower than that of the atopic group with airways reversibility, in agreement with the findings of Turner et $a l^{20}$ and Allan et al. ${ }^{18}$ Although $50 \%$ of the children tested had a first degree relative with a history of allergy, $81 \%$ were atopic on testing, and an increasing percentage developed positive skin tests to $A$ fumigatus with age, both of which favour an acquired rather than a primary inherited defect.

Pancreatic extract is required by all but a few patients with cystic fibrosis. Since this is derived from desiccated hog or beef pancreas, it is rich in foreign proteins and enzymes. Dolan and Meyers $^{10}$ reported five cases of allergic bronchospasm in atopic parents of children with cystic fibrosis and Bergner and Bergner ${ }^{11}$ reported a similar case in a non-atopic patient. Both papers speculated on the possibility that pancreatin acting as an allergen may contribute to the airways disease in cystic fibrosis. Sakula ${ }^{12}$ reported a further case of pancreatin-induced bronchospasm, with serum precipitins present, and a positive skin test to unneutralised Pancrex V. Pancreatin precipitins had been sought but not found by Bergner and Bergner. ${ }^{11}$ Since unneutralised pancreatin contains proteolytic enzymes, it is not unreasonable to expect it to cause a weal on prick testing, and Nakamura ${ }^{21}$ reported a generalised anaphylactic syndrome after pancreatin skin testing. Skin testing with neutralised extract was not, therefore, carried out in this series.

We found no difference between the pancreatin positive and negative precipitin groups in terms of atopy or reversible airways obstruction, or in the mean serum IgE. Thus there is no evidence that pancreatin was a factor in the atopy or airways features of these patients with cystic fibrosis. On theoretical grounds a pancreatic extract containing some trypsin may form a precipitation line with serum containing alpha-1antitrypsin although this does not happen with normal human serum. The exact nature and significance of precipitins to pancreatin is not clear. Indeed, serum precipitins were present in one of our children with cystic fibrosis who had never received pancreatin.

Twenty-nine per cent of our patients showed improved spirometry after salbutamol inhalation. Also the mean FEV $_{1}$ and FVC before bronchodilator of those who responded were no different from those of the patients who did not respond Ten out of 14 children who showed improvement to salbutamol had a history of nocturnal cough or intermittent wheeze at times when the cystic fibrosis appeared to be well controlled, or seasonal worsening of symptoms. Those children without a suggestive history but who had significant reversibility on testing showed maintained improvement of pulmonary function when their asthma was treated. All those with reversible airways disease fell into the atopic category.

The non-atopic group had significantly better spirometry than those who were atopic, but those atopic subjects with a positive prick test to $A$ fumigatus did not have worse spirometry than those who did not. These results differ from those of Silverman et $a l^{5}$ who suggested that patients with positive skin tests to $A$ fumigatus have worse pulmonary function than those with negative skin tests. These and other authors have suggested that the best clinical group of cystic patients are those with atopy, perhaps before the development of $A$ fumigatus hypersensitivity. ${ }^{422}$ However, if the hypothesis for the development of skin hypersensitivity in cystic fibrosis is that with increasing mucosal damage and hence worse airways function, there is increasingly defective clearance of antigen and subsequent sensitisation, it would be more logical for the non-atopic to have the best airways function. Our series shows that the non-atopic have the best mean FEV $_{1}$ and FVC of those tested. Skin hypersensitivity in cystic fibrosis is IgE mediated. ${ }^{19}$ The results of IgE testing show that the non-atopic have significantly lower values, as has been previously reported. ${ }^{18-20}$ The immunology therefore also fits the hypothesis that the non-atopic have the least mucosal damage and hence sensitisation.

Of those patients with reversible airways disease, half (seven patients) had or subsequently developed clinical evidence of allergic bronchopulmonary aspergillosis. This complication of cystic fibrosis was first described by Mearns et $a^{23}$ and subsequently a prevalence of between $0.5 \%$ and $5 \%$ was reported. ${ }^{24} 25$ Those children who have developed this complication in our study have not had very poor lung function, and have been relatively well. Indeed the mean $F_{1} V_{1}$ and mean FVC of those who had developed this complication were no different from those of the 
other atopic children with $A$ fumigatus hypersensitivity.

The frequency of asthma found in our patients was double that found by Rachelefsky et al. ${ }^{4}$ Although the numbers in this subgroup are small, there is good supportive evidence that this is a genuine finding. The asthmatic subgroup were all atopic, had the highest mean IgE, most had a compatible clinical history and half have developed allergic aspergillosis.

The evidence presented shows that in a significant number of children asthma and cystic fibrosis coexist, and that this is IgE-mediated. An association between $A$ fumigatus hypersensitivity and severe lung disease was not found. Skin testing and simple spirometry with bronchodilators will help define those in whom asthma is present, and show those at risk from the development of allergic bronchopulmonary aspergillosis. Hypersensitivity to pancreatin is not thought to play any part in the airways disease of cystic fibrosis.

We would like to thank Mrs P Ormerod for secretarial help.

\section{References}

1 Derbes VJ, Dent JH, White R. Intrinsic (nonallergic) bronchial asthma as a manifestation of fibrocystic disease of the pancreas. J Allergy 1957; 28:287-91.

2 Day G, Mearns MB. Bronchial lability in cystic fibrosis. Arch Dis Child 1973; 48:355-9.

3 Counahan R, Mearns MB. Prevalence of atopy and exercise-induced bronchial lability in relatives of patients with cystic fibrosis. Arch Dis Child 1975; 50:477-81.

4 Rachelefsky MS, Osher A, Dooley RE, Ank R, Stehm R. Coexistent respiratory allergy and cystic fibrosis. Am J Dis Child 1974; 128:355-9.

5 Silverman M, Hobbs FDR, Gordon IRS, Carswell F. Cystic fibrosis, atopy, and airways lability. Arch Dis Child 1978; 53:873-7.

6 Mitchell I, Corey M, Woenne R, Krastins IRB, Levison $H$. Bronchial hyperreactivity in cystic fibrosis and asthma. $J$ Pediatr 1978; 93:744-8.

7 Editorial. Allergy and bronchial hyperreactivity in cystic fibrosis. Lancet 1979; 1:708.

8 Warner JO, Taylor BW, Norman AP, Soothill JF. Association of cystic fibrosis with allergy. Arch Dis Child 1976; 51:507-11.

9 Warner JO, Norman AP, Soothill JF. Cystic fibrosis heterozygosity in the pathogenesis of

10 Dolan TF, Meyers A. Bronchial asthma and $\frac{\bar{\sigma}}{\overline{\frac{5}{5}}}$ allergic rhinitis associated with inhalation of pan- \ำ creatic extracts. Am Rev Respir Dis 1974; 110: ֻ 812-3.

11 Bergner A, Bergner RK. Pulmonary hypersensi- $\vec{\circ}$ tivity associated with pancreatin powder exposure. $\overrightarrow{\vec{\omega}}$ Pediatrics 1975; 55:814-7.

12 Sakula A. Bronchial asthma due to allergy to pancreatic extract, a hazard in the treatment of $\times$ cystic fibrosis. $\mathrm{Br} J$ Dis Chest 1977; 71:295-9. w

13 Cotes JE. Lung function. Third edition. Oxford: $\vec{\circ}$ Blackwell, 1975.

14 Mancini G, Carbonara AO, Heremans JF. مे Immunochemical quantitation of antigens by single radial immunodiffusion. Immunochemistry 1965; 2:235-54.

15 Rowe DS. Radioactive single radial diffusion: a method for increasing the accuracy of immuno- $\frac{0}{0}$ chemical quantifications of proteins in agar gel. $\mathbb{\Phi}$ Bull WHO 1969; 40:613-6.

16 Malo JL, Hawkins R, Pepys J. Studies in chronic $\vec{\bullet}$ allergic bronchopulmonary aspergillosis. 1. Clinical and physiological findings. Thorax 1977; 32: 254-61.

17 Brueton MJ, Ormerod LP, Anderson CM, Shah KJ. Allergic bronchopulmonary aspergillosis complicating cystic fibrosis in childhood. Arch $\frac{\circ}{\mathbb{Q}}$ Dis Child 1980; in press.

18 Alan JD, Moss AD, Wallwork JC, McFarlane $\mathrm{H} . \overrightarrow{\vec{D}}$ Immediate hypersensitivity in patients with cystic 3 fibrosis. Clin Allergy 1975; 5:255-61.

19 Warren CPW, Tai E, Batten JC, Hutchcroft BJ, Pepys J. Cystic fibrosis-immunlogical reactions to $A$ fumigatus and common allergens. Clin Allergy 1975; 1:1-12.

20 Turner MW, Warner JO, Stokes CR, Norman AP. Immunological studies in cystic fibrosis. Arch 3 Dis Child 1978; 53:631-8.

21 Nakamura S. On occupational asthma of different kinds newly found in our asthma clinic. $J$ Asthma Res 1972; 10:37-47.

22 Van Metre TE Jr, Cooke RE, Gibson LE, Winkenwerder WL. Evidence of allergy in patients with cystic fibrosis of the pancreas. JN Allergy 1960; 31:141-50.

23 Mearns MB, Young W, Batten JC. Transient pulmonary infiltrations in cystic fibrosis due $10 \mathrm{~W}$ allergic aspergillosis. Thorax 1965; 20:385-92.

24 Wood RE, Boat TE, Doershuk CF. State of the art-cystic fibrosis. Am Rev Respir Dis 1976; 113:833-78.

25 Mitchell-Heggs P, Mearns MB, Batten JC. Cystic fibrosis in adolescents and adults. $Q J$ Med 1976; 45:479-504. 